\title{
11 \\ The Acquisition of English Stress by Québec Francophones
}

\author{
Guilherme Duarte Garcia and Natália Brambatti Guzzo
}

\subsection{Introduction}

English and French have very distinct prominence systems: while in English stress is assigned at the word level, in French prominence seems to be a property of the (phonological) phrase (PPh). Additionally, word-level stress is contrastive in English (e.g. PREsent vs preSENT). Therefore, stress is a feature that French learners of English as a second language (L2) must acquire.

The objective of this chapter is to investigate the acquisition of English stress by speakers of Canadian French (CF). CF, unlike European French (EF), is argued to exhibit word-level prominence (Walker 1984; Paradis and Deshaies 1990). In this case, producing stress per se should not be a difficulty for CF learners of English (L2ers). However, CF stress is fixed word-finally. Considering that (a) stress in English can emerge in several positions within the word, and (b) factors such as syllable weight and extrametricality play a role in stress assignment, L2ers also need to acquire a novel rhythmic pattern. Another characteristic of the L2 rhythmic pattern is the iterative building of feet, which in English are quantity-sensitive (or weight-sensitive) trochees (e.g. [ækə][démık] 'academic'; [pæsə][dí:nə] 'Pasadena'). Although some authors argue that (Canadian) French also has foot structure (e.g. Goad and Buckley 2006), CF would still be considerably different from English, as feet would be iambic (i.e. right-headed) and non-iterative.

In this chapter, we report the results of two production experiments (one in CF and one in English) aimed at examining how advanced CF L2ers produce English stress. In other words, our focus is not on language development (i.e. whether learners actually acquire stress in English), but rather on ultimate attainment in L2 acquisition (i.e. how native speakers 
and advanced learners compare vis-à-vis stress production). In order to evaluate whether L2ers' rhythmic patterns mirror native English patterns, we compare L2ers' production with control data, focusing on three possible acoustic correlates of prominence: duration, pitch (F0) and intensity. To verify whether L2ers transfer acoustic cues or rhythmic patterns from their first language (L1) into the L2, we also analyse how prominence is produced by L2ers in their L1.

We found that duration is the main phonetic dimension employed by L2ers to produce target-like word-level prominence in English. Duration is also the main correlate of the alternating rhythmic patterns in L2ers' production. With regard to CF, we found no phonetic evidence for word-level prominence nor word-internal constituency, which indicates that stress and foot structure are properties that L2ers must acquire. Overall, L2ers do show target-like patterns vis-à-vis prominence and rhythm, and their use of duration is strikingly similar to the trends observed in the target language.

This chapter is organized as follows: In Section 11.2, we discuss prominence/stress in French and English, and report the results of some studies which have examined the acquisition of English stress by native French speakers. In Section 11.3, we present the methodology of our experiment. In Section 11.4, we discuss our data and present our statistical analyses. In Section 11.5, we briefly discuss the phonological implications of our results.

\subsection{Stress in French and English}

\subsubsection{French Stress}

Cross-linguistically, it is assumed that the phonological word (PWd) is the prosodic domain in which primary stress is assigned (Nespor and Vogel 1986; Selkirk 1986). In European French (EF), however, the domain of prominence is traditionally considered to be the phonological phrase (PPh), the constituent that immediately dominates the PWd (Jun and Fougeron 2000; Gussenhoven 2004). Within the French PPh, the rightmost syllable of the rightmost PWd exhibits prominence (1a). If the rightmost syllable has a schwa, prominence is placed on the preceding syllable (1b). The examples in (1) are taken from Tremblay (2007: 28). 


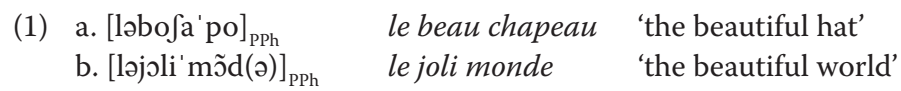

On the other hand, some authors have argued that in Canadian French (CF) prominence is assigned in the PWd domain (Walker 1984; Paradis and Deshaies 1990). In other words, each PWd in a PPh in CF should have a primary stress (2). The examples in (2) are in Paradis and Deshaies (1990: 148).

(2) $[\varepsilon \text { le 'teply' gRos }]_{\mathrm{PPh}}[\mathrm{kynp \varepsilon R} \text { 'son }]_{\mathrm{PPh}}$ [œẽnã' fãnoR 'mal $]_{\mathrm{PPh}}$ Elle était plus grosse qu'une personne... un enfant normal.

'She was bigger than a person... a normal child.'

In both $\mathrm{EF}$ and $\mathrm{CF}$, prominence is related to greater duration (e.g. Garde 1968; Walker 1984). In EF, prominent syllables also have higher pitch (e.g. Garde 1968). In CF, however, some vowels are considered inherently long (3) and seem to exhibit a certain degree of prominence, regardless of their position in the PWd or the PPh (Walker 1984; Armstrong 1999; Tremblay 2007).

(3) Long vowels in CF:

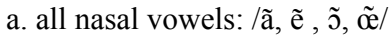

b. some oral vowels: /a, o, $\varepsilon, \varnothing /$

c. vowels followed by /3, R, v, z/ in coda position

Inherently long vowels in CF are often associated with a phenomenon known as pretonic lengthening (or penultimate stress) (4). When a long vowel is in penultimate position in CF, it can arguably bear either a secondary stress (if the final vowel is long) or even the main stress in the word (if the final vowel is not inherently long). In other positions in the word, inherently long vowels are also perceived as stressed. In the examples in (4), the vowels [œе̃, ø] can be perceived as stressed [as per (3) above], even though they are in penultimate position (examples from Paradis and Deshaies 1990: 151).

(4) [loẽdzi $]$ lundi 'Monday' [døzjem] deuxième 'second'

Another characteristic of CF is l'accent d'insistance, or emphatic stress (5). Emphatic stress dislocates prominence onto a non-final syllable of the $\mathrm{PPh}$, and is often associated with emotional or passionate speech. The examples in (5) are from Walker (1984: 32). 


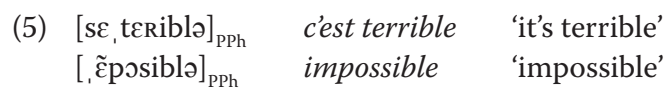

According to Thibault and Ouellet (1996), both emphatic stress and pretonic lengthening emerge from pitch movements in the phrasal or word domain. However, whereas emphatic stress involves a $\mathrm{L}+\mathrm{H}^{*}$ (low-high) tone combination on the emphasized syllable, pretonic lengthening results from the assignment of a $\mathrm{H}+\mathrm{L}^{*}$ tone to the target syllable.

Another characteristic of French prominence (both in EF and in CF) is phrase-initial prominence (e.g. Gussenhoven 2004; Goad and Buckley 2006; Goad and Prévost 2011). Although some instances of phrase-initial prominence in $\mathrm{CF}$ derive from emphatic stress, this form of prominence seems to be the result of a boundary effect (Gussenhoven 2004) (6).

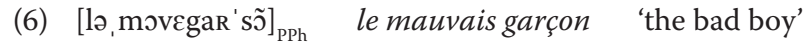

Phrase-initial prominence is also associated with pitch (Jun and Fougeron 2000): a high tone is assigned to a syllable of the leftmost PWd in the PPh. The syllable with phrase-initial prominence is usually the first syllable of the first PWd in the PPh (7a), but other syllables of such PWd may also bear prominence (7b). The examples in (7) are in Gussenhoven (2004: 253).

(7) a. ENfant adoptif 'adoptive child'

b. enFANT adoptif

Phrase-initial prominence, as well as emphatic stress, is arguably optional in CF. Pretonic lengthening, on the other hand, is an effect of vowel quality and is therefore not optional. However, it is not clear in the literature whether the application of pretonic lengthening overrides phrase-final (or word-final) prominence.

Stress in both EF and CF is not iterative, which has led some researchers to argue that the language has no foot structure (e.g. Jun and Fougeron 2000; Özçelik 2011). A theoretical consequence of such an assertion is that the foot $(\mathrm{F})$ is not a universal domain (contra, for example, Nespor and Vogel 1986), and that PWds in certain languages may be formed directly from the combination of syllables. Nevertheless, some other scholars consider that prominent syllables correspond to foot heads in French. As a result, in phrases with initial prominence, two binary feet are constituted: the leftmost foot is trochaic, i.e. with prominence on the initial syllable, while the rightmost foot is iambic, i.e. with prominence on the final syllable (Goad and Buckley 2006) (8). 


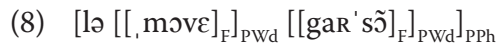

Although researchers seem to agree on the fact that (Canadian) French exhibits prominence on the right edge of the $\mathrm{PPh}$, two facts compromise the classification of such prominence as stress: (a) the fact that prominence can apparently shift to previous syllables, and (b) the fact that prominence does not follow any specific rhythmic pattern, but is assigned to phrasal edges (both left and right). These observations have contributed to categorizing French as an intonation-only language (Gussenhoven 2004). If Canadian French is an intonation-only language (as opposed to a stress language), then stress is a feature that English L2ers must acquire. In the next section, we present the main characteristics of English stress and briefly report the results of some experimental studies that have focused on the production or perception of English stress by native French speakers.

\subsubsection{Acquisition of English Stress}

Several seminal studies in the past decades have investigated English stress (Chomsky and Halle 1968; Liberman and Prince 1977; Hayes 1982; Halle and Vergnaud 1987 and many others since then). As a whole, we observe several robust tendencies in English vis-à-vis its stress patterns. In other words, stress is relatively predictable in the language. On the other hand, we should note that there is evidence that words in the lexicon already have metrical information (Selkirk 1980), which could indicate that stress in English may be less predictable than what is often assumed.

When we compare English and French, we might say that stress is one of the most explicit phonological differences between these two languages. For example, unlike French, where prominence is assigned to either the PPh or the PWd (Section 11.2.1), English licenses (primary and second- ary) stress on multiple positions in a word. Another important difference between the languages is that stress in English is influenced by syllable weight, that is, heavier syllables (see (9)) are more likely to attract stress than light syllables. In verbs and adjectives, stress falls on the final syllable if it is heavy (9a) - heavy syllables may contain a long vowel or a complex coda. If this syllabic condition is not met, stress falls on the penultimate syllable (9b). Nouns, on the other hand, have penultimate stress if the pen- ultimate syllable is heavy (9c), and antepenultimate stress otherwise (9d). Final stress is generally avoided, but may emerge if the word-final coda is complex, for example (9e). 
(9) a. verbs and adjectives with heavy final syllables: direct, supreme

b. verbs and adjectives with no heavy final syllable: accomplish, tired

c. nouns with heavy penult syllable: agenda, Arizona

d. default antepenult stress in nouns: Canada, quality

e. nouns with a complex final coda and a light penult syllable: request

Even though stress in (i) verbs and adjectives and (ii) nouns is influenced by syllable weight, these two classes of words follow slightly different stress patterns. The differences are mostly concentrated on the wordfinal syllable, which requires a specific syllabic shape to be stressed. Hayes (1982) proposes a unified analysis based on extrametricality that accounts for both classes: whereas in nouns a light final syllable is extrametrical, in verbs and adjectives it is the final consonant that is extrametrical.

Naturally, the behaviour of word-final syllables in English makes the acquisition of its stress system more challenging to French speakers. Learners need to assign stress to different positions in a word, and which syllable bears stress depends not only on weight but also on word class and other (less predictable) factors.

Overall, one would think that final stress in English would be easier for French speakers, given their L1 system. However, in a comprehensive perception study, Altmann (2006) shows that advanced learners of English (L1 French) performed less well in words with final stress in the target language.

In a study about the processing of word stress by CF learners of English, Tremblay (2008) found that the L2ers who were able to discriminate between English words based on stress contrast were especially the ones with target-like knowledge of stress placement. On the other hand, in a study on the production of English word stress by CF learners of various proficiency levels, Tremblay and Owens (2010) found a preference for stress on the first syllable for both disyllabic and trisyllabic words. However, most of the learners did not assign stress correctly in trisyllabic words with a stressed heavy syllable. L2ers who showed a preference for stress at the left edge of the word used pitch as the main correlate, while L2ers who stressed the penultimate syllable used duration.

A crucial consequence of the differences between French and English stress is the existence of word-level constituents (i.e. feet): whereas English clearly has a rhythmic pattern, French does not. For example, the word academic has penultimate primary stress and initial secondary stress: (àca)(démic). Since stress is the prominence of a unit (e.g. syllable) relative to its neighbouring units, it is essential that learners also perceive and produce non-primary prominences in their $\mathrm{L} 2$. 
The phonetic realization of stress in English is, as expected, very different from French (Section 11.2.1). Traditionally, stress in English is correlated with pitch (Fry 1955, 1958; Grimson 1980; Lehiste 1976). However, studies have shown that duration and intensity also play an important role in distinguishing stressed and unstressed syllables in the language (Lieberman 1960; Beckman 1986; Laver 1994; Harrington, Beckman, Fletcher and Palethorpe 1998). In other words, multiple phonetic cues signal word-level prominence in English, which likely makes stress perception and production in English even more challenging to French speakers.

Learners also need to deal with non-primary prominences, which are responsible for the rhythmic pattern in English stress mentioned above (i.e. word-level constituency). Gussenhoven (2004) shows some evidence that duration also plays an important role in distinguishing these secondary prominences from primary stress. Plag, Kunter and Schramm (2011), however, show that the evidence is not strong in North American English: if duration is in fact a cue for distinguishing primary and secondary stresses, it is certainly very subtle.

In sum, for French-speaking learners of English to be target-like, they have to first learn that word-level prominence is crucial in the language. Second, they have to be able to shift prominence within each word, since most English words will have penultimate or antepenultimate stress. Third, they need to acquire word-level constituency (weight-sensitive trochaic feet in this case), which will allow them to produce target-like rhythmic patterns. In the present study, we investigate (i) whether these three aspects are indeed acquired by advanced L2ers and, if so, (ii) how these aspects are phonetically realized in the vowels of PWds.

\subsection{Methodology}

If we assume that CF, as EF, has no word-level prominence, then English L2ers must acquire stress. In this case, two hypotheses can be formulated:

(i) English L2ers do not acquire word-level stress in English, therefore, what is perceived as stress in L2ers' production is perhaps the result of boundary effects transferred from their L1 into the L2 (i.e. no acoustic correlate is significant for prominence at the word level, and both L1 and L2 have similar rhythmic patterns); or

(ii) English L2ers can acquire stress in English (i.e. some syllables in the word domain are reinforced, and some rhythmic patterns can be 
identified), even though stress may not be produced in a target-like manner.

On the other hand, if we assume that CF does have word-level prominence and that prominence is fixed word-finally in the language, then English L2ers must acquire a different rhythmic pattern, but not stress per se. In that case, two other hypotheses can be formulated:

(i) English L2ers produce English stress using the same acoustic correlates and/or following the same rhythmic pattern (word-final stress) as in their L1; or

(ii) English L2ers produce English stress in a target-like manner (i.e. using the target-like rhythmic pattern and acoustic correlates that are potentially different from those they use in their L1).

Another hypothesis for this scenario is that CF speakers acquire stress in a semi-target-like manner, with elements from both their L1 and the L2 in their interlanguage grammar. Additionally, like some participants in Tremblay and Owens' (2010) experiment on nonce word production, they may use different acoustic correlates in order to signal stress in different positions within the PWd.

In order to test these hypotheses, two production experiments were conducted: one in CF (participants' L1) and the other in English (participants' L2). In the CF version of the experiment, the target-phrases $(n=24)$ were formed by combinations of adjective+noun (e.g. mauvais garçon 'bad boy'), noun+preposition+noun (e.g. maison $d u$ chocolat 'house of chocolate'), and adjective+noun-adjective (e.g. dernier candidat japonais 'last Japanese candidate'). The carrier sentence was Elle a vu le/la/un/une [target phrase] ('She saw the/a/an [target phrase]'). Two words in each phrase were analysed $(\mathrm{n}=48)$.

In the English version of the experiment, the target phrases $(n=200)$ were formed by combinations of adjective+noun (e.g. adorable musician), noun+preposition+noun (e.g. minister of economy), and adverb+adjective+noun (e.g. completely frequent request). Two carrier sentences were used: She saw the/a/an [target phrase] and She saw the/a/an [target phrase] before class. Because the number of words analysed in each phrase varied ( 1 or 2 ), the total number of words examined was 374 (final stress $=98$; penult stress=106; antepenult stress=136; pre-antepenult stress=34).

In both versions of the test, all vowels in the words on both left and right edges of the target phrases were considered, in order to test whether L1 boundary effects were also found in speakers' L2. Target words in both CF and English had a minimum of two syllables (e.g. maison 'house', request). 
In the CF experiment, target words had a maximum of three syllables (e.g. historique 'historical'), while in the English experiment target words had a maximum of five syllables (comparatively). In target English words, stress could be final (e.g. request, complete), penultimate (e.g. damage, dramatic), antepenultimate (e.g. senator, chemical) and pre-antepenultimate (e.g. secretary, comparatively). Position of stress was not controlled in $\mathrm{CF}$, as it was assumed that, if stress is present at the PWd domain in the language, it should be final for all target words in the experiment. All vowels in both English and French target words were measured for duration, pitch (F0) and intensity. The Appendix lists the words analysed in the experiments.

Participants (6 L2ers, 2 of them female; 2 English controls, 1 of them female) were recorded in a soundproof booth. All L2ers had an advanced level of proficiency in English, as they used the language on a regular basis for study or work purposes. They were all born in Quebec and lived in Montreal at the time of the experiment. Their ages ranged from 20 to 36 years, and all participants were prepubescent learners. Considering that our participants are advanced in the target language, we expect one of the hypotheses labelled as (ii) above (that L2ers can produce word-level stress in English following target-like patterns) to be confirmed.

Our French data was forced-aligned using Milne's (2012) SPLaligner. Later, a random sample of aligned sentences was manually checked. The English data was manually aligned and transcribed.

\subsection{Results}

Because the present study investigates the manifestation of duration, pitch and intensity in vowels in PWds, this section is divided into three parts, each of which will describe and explore the data in terms of a specific phonetic correlate. Results from each correlate will be described across all three groups of participants, namely, L1 English $(n=2)$, L1 French $(n=6)$ and L2 English $(n=6)$ - the data from L1 French and L2 English were produced by the same participants. The plots used in this section include means and error bars. If two error bars do not overlap (or overlap slightly), then the values they represent are likely significantly different (overall).

The data were modelled using mixed-effects linear regressions $(\operatorname{lmer}()$ in $\mathrm{R})$, all of which predicted the value(s) of a given phonetic correlate based on the different vowels examined. All models reported below include by-speaker random effects (which mirror the interactions or main effects included in each model) as well as a by-item random intercept. Upon 
inspection, all models have an unbiased residual distribution. We excluded English words with pre-antepenultimate stress from our data, to keep the analysis focused on the three stress positions found in monomorphemic words.

Recall that all participants in this study are advanced in their L2. As a result, it is expected that these L2ers will be target-like regarding the most prominent syllable in the word: in fact, L2ers $(n=6)$ were on average $92.6 \%$ accurate in producing the correct stressed word ( $\mathrm{SD}=3.8 \%)$. Only words that were accurately produced by all L2ers are considered in the analyses presented below.

\subsubsection{Duration}

As discussed in Section 11.2.2, duration is often considered a robust correlate of English stress in the literature (e.g. Beckman 1986; Gussenhoven 2004). This is also confirmed in our results. In Figure 11.1, target vowels are on the $\mathrm{x}$-axis (V1=word-final vowel; V2-V4=word-internal vowels), and the normalized duration of each vowel is on the $y$-axis (duration, pitch and intensity were normalized by speaker; the values used throughout this chapter are therefore scaled and centred around mean zero, z-scores). In addition, the plots are faceted by stress position: antepenultimate, penultimate and final. In native English, duration clearly correlates with stress across all stress positions. The rhythmic pattern in words such as academic [(àca)(démic)] is also mirrored in the duration of each vowel in the word (e.g. plot 2 in Figure 11.1).

As suggested by the error bars in Figure 11.1, the differences in duration across vowels are significant. For example, if we examine words with

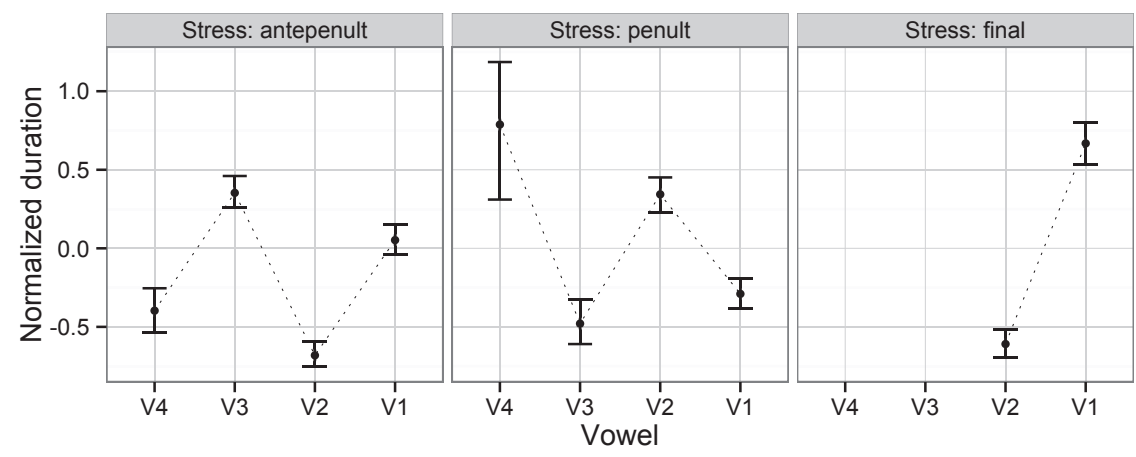

Figure 11.1. Normalized duration of different vowels in target words by stress position: English controls. V1=right edge of the word. 
final stress and model the standardized duration based on vowel position (V1 and V2), we find that V1 has a significant effect on duration. In other words, V2 and V1 are significantly different even when we account for by-item and by-speaker variation (V2: $\hat{\beta}=-1.78, \mathrm{t}=-15.46, \mathrm{p}<0.0001)$. In other words, V2 is shorter than V1 by 1.78 standard deviations. Likewise, in words with penult stress, V1 and V2 are significantly different $(\hat{\beta}=-0.90$, $\mathrm{t}=-12.16, \mathrm{p}<0.0001)$, as well as V3 and V2 $(\hat{\beta}=-0.91, \mathrm{t}=-9.13, \mathrm{p}<0.0001)$. Given Figure 11.1, it is unsurprising that the difference between V2 and $\mathrm{V} 4$ are less significant for words with penult stress (V4: $\hat{\beta}=0.85, t=2.49$, $\mathrm{p}=0.0133)$. For words with antepenult stress, V1, V2 and V4 are all significantly different from V3, as suggested by the error bars in Figure 11.1.

The duration patterns in our Canadian French data, as expected, look very different. Even though we do see some gradual trend in Figure 11.2, it is no longer clear that duration is invariably different in word-final vowels. We see, however, a clear effect of penult vowel length: in a word such as batîment ('building'), for example, the penult vowel is short, whereas in maison ('house') the penult vowel is inherently long. As a result, whether the final vowel is phonetically longer relative to previous vowels depends on whether an inherently long vowel immediately precedes it. Note, too, that unlike the English data in Figure 11.1, these data do not suggest any alternating rhythmic pattern within the word - which is consistent with the analyses reported in Section 11.2.1. Therefore, we can see that the differences discussed in Section 11.2 are mirrored in the empirical data thus far.

A statistical model confirms the interaction we see in Figure 11.2, namely, that the differences in duration between V1 and V2-V3 are only significant if V2 is short $(\hat{\beta}=0.82, \mathrm{t}=2.2, \mathrm{p}=0.04)$. No main effects are significant, which confirms that duration in itself is not a robust correlate in these data. Finally, phrase edge had no effect on duration.

Let us now examine the patterns produced by L2ers in English. The question of interest is how L2ers assign prominence, and whether they present target-like rhythmic patterns. The first thing we note in Figure 11.3 is its resemblance to Fig 11.1: not only are L2ers' vowels longer when stressed, but the alternating rhythmic pattern is clearly seen across syllables V1-V4 in words with antepenult or penult stress.

One interesting fact about the data presented above is that the trends observed are very similar regardless of which PPh edge we examine. For example, in a phrase such as minister of economy, both PWds exhibit the duration patterns illustrated above. This is particularly relevant under the assumption that French only has phrase-final prominence (Jun and Fougeron 2000; Gussenhoven 2004), since L2ers would then have to learn to assign prominence to phrase-initial words in the L2. 


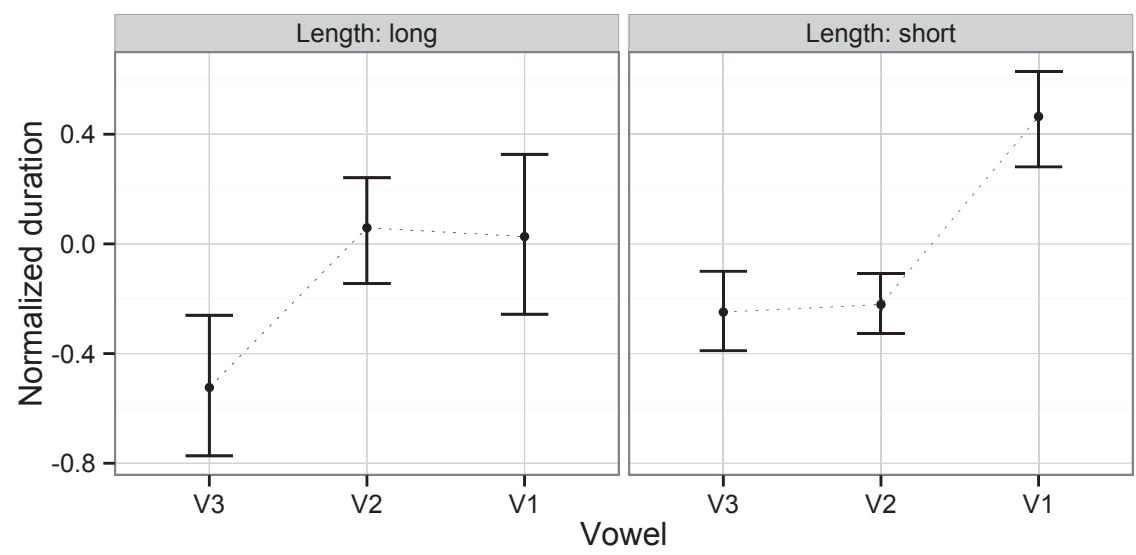

Figure 11.2. Normalized duration of different vowels in target words: French controls. V1=right edge of the word. 'Long' and 'short' refer to V2.

As suggested by Figure 11.3, V2 and V1 are significantly different even when we account for by-item and by-speaker variation (V2: $\hat{\beta}=-1.53$, $\mathrm{t}=-8.10, \mathrm{p}<0.0001)$. In other words, $\mathrm{V} 2$ is shorter than $\mathrm{V} 1$ by 1.53 standard deviations. Likewise, in words with penult stress, V1 and V2 are significantly different $(\hat{\beta}=-0.72, \mathrm{t}=-11.95, \mathrm{p}<0.0001)$, and so are V3 and V2 $(\hat{\beta}=$ $-0.43, \mathrm{t}=-4.09, \mathrm{p}<0.01)$. Given Figure 11.1, it is unsurprising that $\mathrm{V} 2$ and $\mathrm{V} 4$ are not significantly different for words with penult stress (V4: $\hat{\beta}=0.04$, $\mathrm{t}=0.13, \mathrm{p}=0.90$ ). For words with antepenult stress, V1, V2 and V4 are all significantly different from V3, as suggested by the error bars in Figure 11.1. Neither position in the sentence (final vs non-final) nor phrase edge (left vs right) had a significant effect on duration.

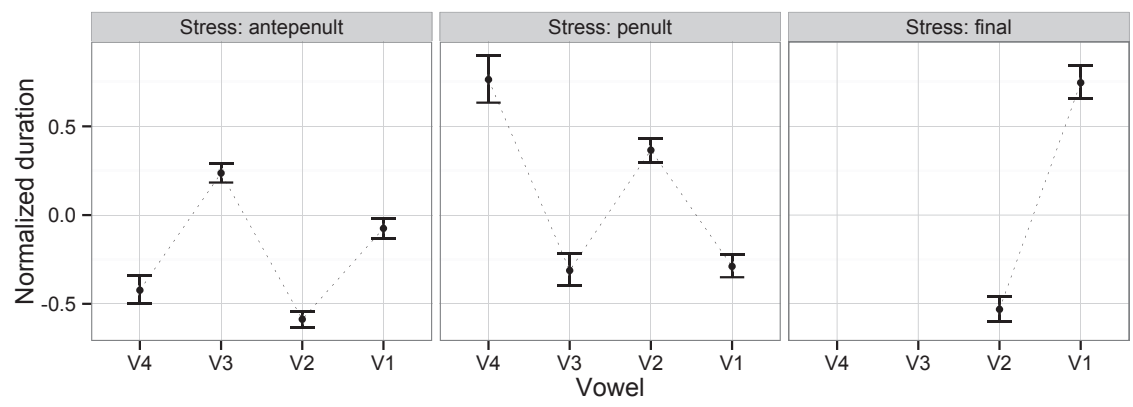

Figure 11.3. Normalized duration of different vowels in target words: L2ers. V1=right edge of the word. 


\subsubsection{Pitch}

In Figure 11.4, we can see the normalized pitch of our English controls. Unlike Figure 11.1, we observe a trend that is less clear, in that no explicit correlation between pitch and stress is observed for all positions. In this particular case, our data could only partly capture the correlation between pitch and stress which is found in the literature (e.g. Lehiste 1976). For penult and final stress, we can see that pitch rises towards the more prominent vowel. The distribution of the data is considerably sparse (bimodal in some cases), which is likely due to our control sample size. Importantly, these results are not inconsistent with what is known about stress in English.

For words with final stress in Figure 11.4, no significant difference was found between V2 and V1 (V2: $\hat{\beta}=-0.17, t=-1.07, p=0.28)$. For words with penult stress, the pitch of V3 was significantly different from V2 at $\alpha=0.05$ $(\hat{\beta}=-0.38, \mathrm{t}=-2.04, \mathrm{p}=0.04)$.

As expected, phrase position seems to have an effect on the different pitch patterns: while phrase-final words with penult stress had a descending pitch, words in non-final positions had an ascending (or neutral) pitch pattern overall. This difference, however, was not significant in a model that included an interaction between vowel and position (final vs nonfinal). Finally, for words with antepenult stress, no significant difference in pitch was found among English-speaking controls, which is not surprising given the trends observed in Figure 11.4.

In French, we can see some correlation between pitch and prominence. In Figure 11.5, the pitch of the word-final vowel (V1) is higher relative to vowels V2 and V3. The amount of variation is similar across all three

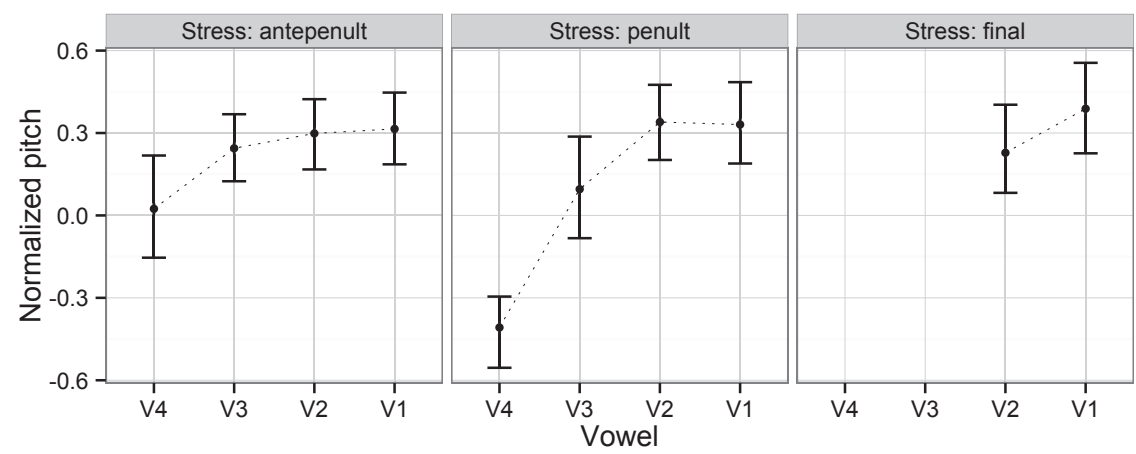

Figure 11.4. Normalized pitch of different vowels in target words: English controls. $\mathrm{V} 1$ = right edge of the word. 


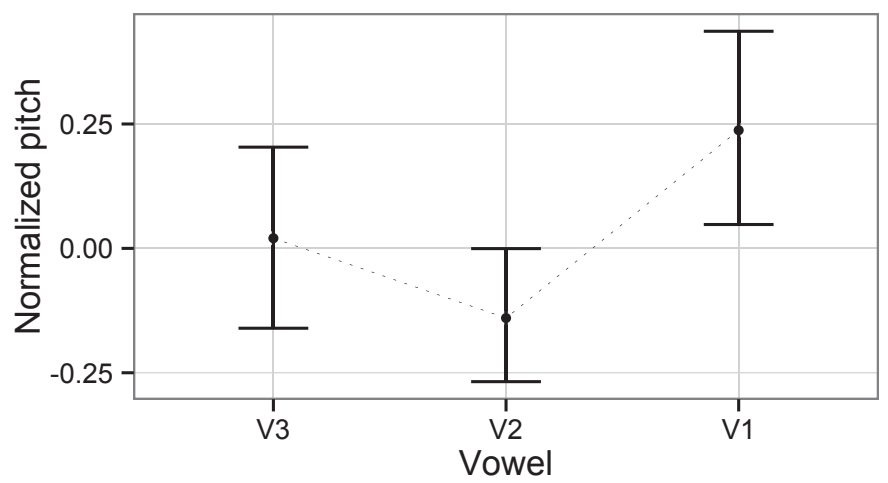

Figure 11.5. Normalized pitch of different vowels in target words: French controls. $\mathrm{V} 1$ = right edge of the word.

syllables (regardless of phrase edge). Therefore, our data suggest that pitch seems to play a role vis-à-vis word-level prominence in CF. However, once we take into account by-speaker (and by-item) variation, no significant pitch difference is found between V1 and V2 $(\hat{\beta}=-0.35, \mathrm{t}=-1.47, \mathrm{p}=0.20)$ and V1 and V3 ( $\hat{\beta}=-0.10, t=-0.43, p=0.68)$. Unlike with duration, there is no significant interaction between pitch and the length of the penult vowel in the word.

Let us now turn to L2ers' production, shown in Figure 11.6. As with duration, we can see that L2ers' pitch patterns seem to be overall correlated with stress: higher pitch values are found in more prominent syllables (note, for example, the differences between stressed syllables and preceding syllables).

In words with final stress, V1 and V2 in Figure 11.6 suggest a significant difference. However, once we take into account by-speaker variation,

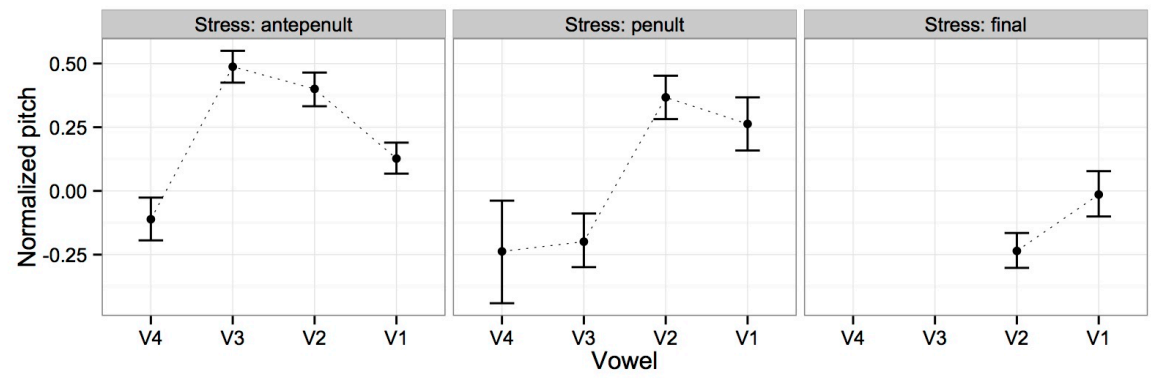

Figure 11.6. Normalized pitch of different vowels in target words: L2ers. $\mathrm{V} 1$ = right edge of the word. 
that difference is not significant $(\hat{\beta}=-0.09, \mathrm{t}=-1.77, \mathrm{p}=0.07)$. In words with penult stress, V2 is significantly different from V3 (V3: $\hat{\beta}=-0.4, t=-3.03$, $\mathrm{p}=0.02)$. V1 and V4 are not significantly different from V2. Finally, in words with antepenult stress, V1 and V4 are both significantly different from V3 vis-à-vis pitch $(V 1: \hat{\beta}=-0.52, t=-2.88, p=0.03 ; V 4: \hat{\beta}=-0.53, t=-2.85$, $\mathrm{p}=0.03)$. No interaction between vowels and position in the phrase was observed in the data.

\subsubsection{Intensity}

In the previous sections, we saw that L2ers' production showed a clear correlation between stress, duration and pitch. In this section, we will see that intensity, like duration, also plays a role. In Figure 11.7, for example, we see our control data, which suggest a clear correlation between intensity and stress. This correlation, however, is not as robust as expected once by-speaker variation is taken into account.

In words with final stress, for example, no significant difference is found between the intensity of V2 and V1 (V2: $\hat{\beta}=0.10, t=0.92, p=0.47)$. Likewise, in words with penult stress, V4, V3 and V1 are not significantly different from V2 in our data - note, however, that the trend observed is exactly what one would expect given what is known about stress in English, i.e. a positive correlation between word-level prominence and intensity. Finally, in words with antepenult stress, V1, V2 and V4 all have significantly lower intensity than V3 $(\mathrm{V} 1: \hat{\beta}=-1.01, \mathrm{t}=-14.26, \mathrm{p}<0.0001 ; \mathrm{V} 2: \hat{\beta}=-0.79, \mathrm{t}=-11.20$, $\mathrm{p}<0.0001 ; \mathrm{V} 4: \hat{\beta}=-0.37, \mathrm{t}=-3.46, \mathrm{p}<0.001)$.

In French, intensity does not seem to correlate with word/phrase-final prominence (Figure 11.8). Instead, what we see is a flat pattern for words at the left edge of the phrase, and a descending pattern for words at the right

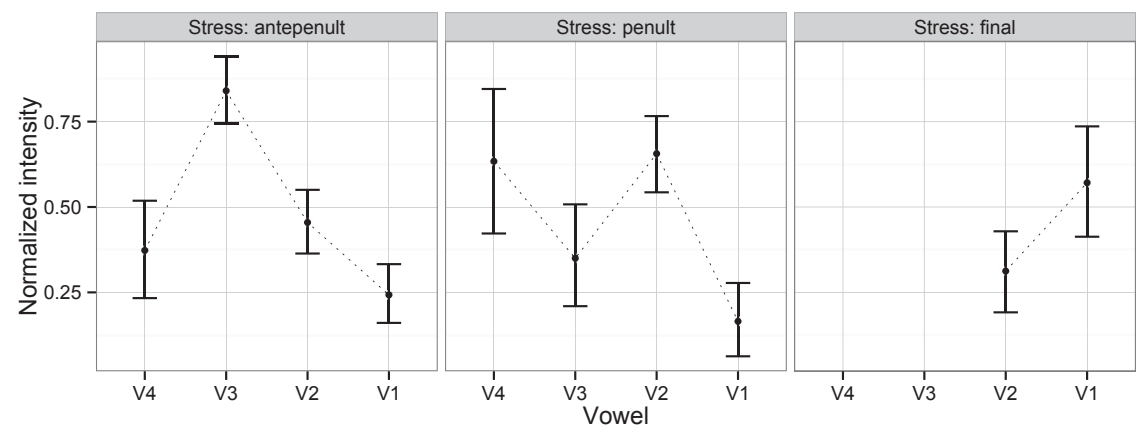

Figure 11.7. Normalized intensity of different vowels in target words: English control. $\mathrm{V} 1$ = right edge of the word. 
edge (as expected, given this is the final word in the phrase). This result is consistent with the literature, as prominence in French is not associated with loudness. In fact, a regression model that includes an interaction between vowel and edge confirms that V3 has overall significantly higher intensity than V1 $(\hat{\beta}=0.46, \mathrm{t}=3.37, \mathrm{p}<0.001)$, and that both V2 and V3 have significantly higher intensity than $\mathrm{V} 1$ at the right edge $(\mathrm{V} 2: \hat{\beta}=0.34, \mathrm{t}=2.42$, $\mathrm{p}=0.016$; V3: $\hat{\beta}=0.48, \mathrm{t}=2.61, \mathrm{p}=0.009$ ). In other words, there is no clear positive correlation between intensity and word-level prominence in our CF data (if we assume that CF PWds exhibit final prominence).

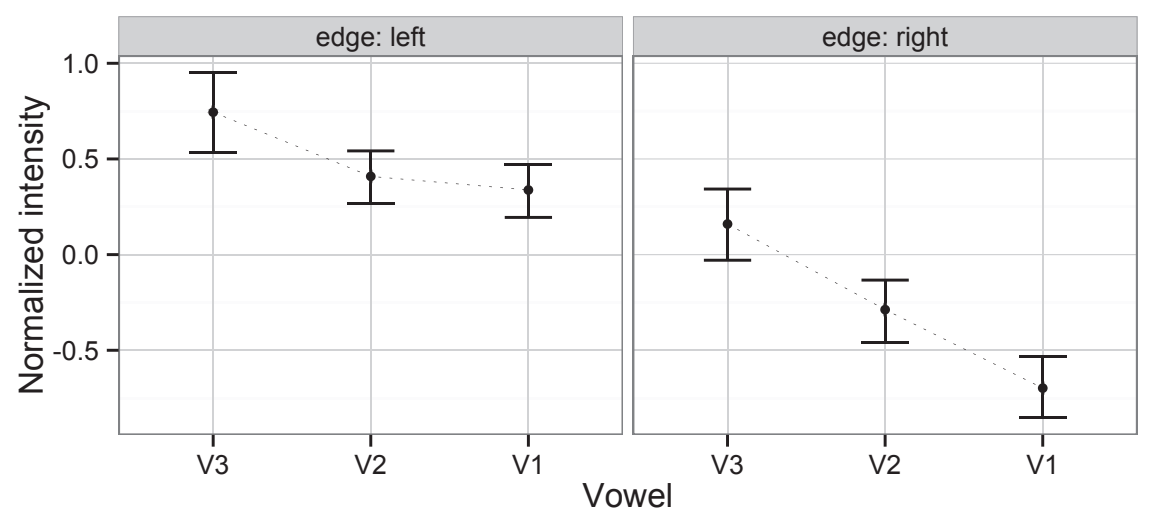

Figure 11.8. Normalized intensity of different vowels in target words by PPh edge: French controls. V1 = word-final vowel.

Looking at L2ers' production data, we see a pattern that resembles that of Figure 11.7. Stress and intensity seem to be correlated (note that very few data points with penultimate stress contain more than three vowels in Figure 11.9).

In words with final stress, penult vowels (V2) have significantly lower intensity than final vowels (V1): $\hat{\beta}=-0.25, \mathrm{t}=-4.35, \mathrm{p}<0.0001$. In words with penult stress, both $\mathrm{V} 3$ and $\mathrm{V} 1$ have significantly lower intensity than V2 (V3: $\hat{\beta}=-0.36, t=-5.30, p<0.0001 ; \mathrm{V} 1: \hat{\beta}=-0.93, \mathrm{t}=-18.77, \mathrm{p}<0.00001$ ). Finally, in words with antepenult stress, V1, V2 and V4 all have significantly lower intensity than $\mathrm{V} 3$, the most prominent vowel in the word (V1: $\hat{\beta}=-0.99, t=-23.97, p<0.00001 ; \mathrm{V} 2: \hat{\beta}=-0.77, t=-18.63, p<0.00001 ; \mathrm{V} 4: \hat{\beta}=$ $-0.55, \mathrm{t}=-9.47, \mathrm{p}<0.00001)$.

Importantly, the intensity of V2 and V3 in Figure 11.9 rises in relation to its surrounding vowels in words with penultimate and antepenultimate stress, respectively. This mirrors what we see in our control data (Figure 11.7). 


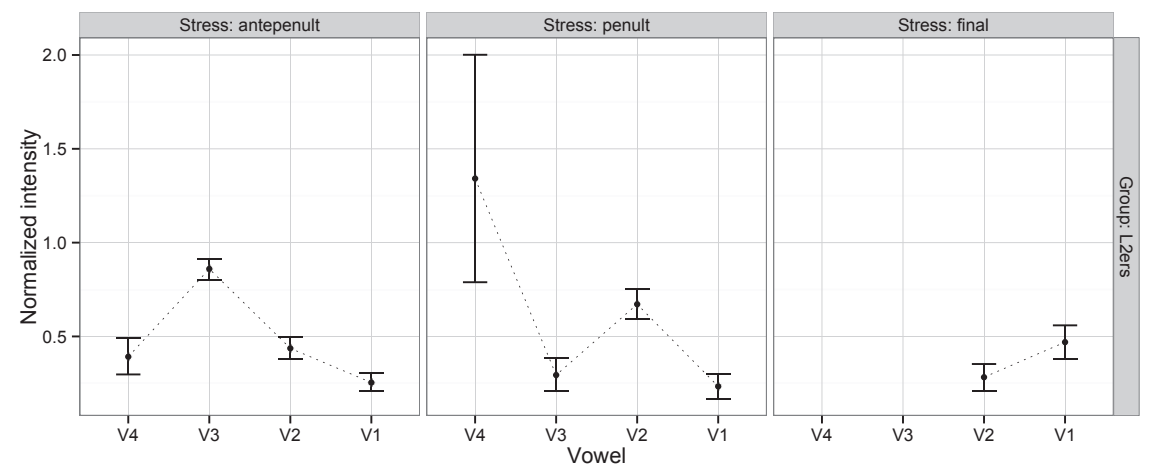

Figure 11.9. Normalized intensity of different vowels in target words: L2ers. V1 = right edge of the word.

In sum, the data show robust (and target-like) correlations between stress, duration, pitch and intensity in L2ers' production. Crucially, these patterns are clearly different from what we see in our CF data. It is important to note, however, that duration, pitch and intensity are naturally not completely orthogonal. Indeed, among L2ers' data, duration is significantly correlated with intensity $(\mathrm{r}=0.16, \mathrm{p}<0.0001)$ and pitch $(\mathrm{r}=-12, \mathrm{p}<0.0001)$; and intensity is significantly correlated with pitch $(r=0.31, p<0.0001)$. Such collinearity indicates that we cannot be completely certain about the role of each of these acoustic correlates taken independently given the data.

Note, however, that all three cues examined above showed no clear correlation with L1 prominence. Even though duration is often said to be the most robust correlate of prominence in French, L2ers are not merely transferring the duration patterns present in their L1. Rather, they accurately produced the rhythmic patterns observed in our control data - indeed, rhythmic patterns are observed through duration and intensity. In other words, regardless of the orthogonality of the phonetic correlates measured, it is clear that L2ers are not merely applying their L1 patterns to the L2.

\subsection{Implications and Final Remarks}

Our results for duration, pitch and intensity in CF provide no evidence to support the suggestion that this language has word-level stress or wordinternal constituency. Thus, what is perceived as prominence in CF may in fact be the result of phrasal boundary effects. This is in line with what some 
researchers have proposed for EF prominence (e.g. Jun and Fougeron 2000; Gussenhoven 2004) and for internal constituency in both EF and CF (Jun and Fougeron 2000; Özçelik 2011).

The results from our CF data have two main implications: (a) prominence may not be a property of the phonological word (PWd), and (b) word-internal constituency (i.e. foot structure) is not universal. Implication (a) contradicts the traditional notion of PWd (e.g. Nespor and Vogel 1986), according to which such constituent corresponds to a lexical stem (plus incorporated elements, such as prefixes and suffixes), and is the domain where primary stress is assigned. However, recent analyses (e.g. Vogel 2009) exclude primary stress assignment as one of the exclusive properties of the PWd.

Implication (b), on the other hand, alters the notion of the prosodic hierarchy (Selkirk 1984; Nespor and Vogel 1986) as the universal scale of suprasegmental domains in which specific phonological processes apply. In the partial representation of the universal prosodic hierarchy presented in (10), we notice that the constituent that immediately dominates the syllable $(\sigma)$ is the Foot, which in turn is dominated by the PWd. If we assume that certain languages have no foot structure, then the Foot is not a universal prosodic domain, but a parametric domain (Özçelik 2011). This means that, while feet may be activated in the grammar of some languages, it may be absent in other languages. The representation in (11) illustrates the partial prosodic structure of CF. Note that the constituent that immediately dominates the syllable in (11) is the PWd.

(10)

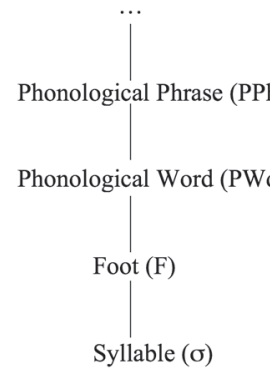

$(11)$

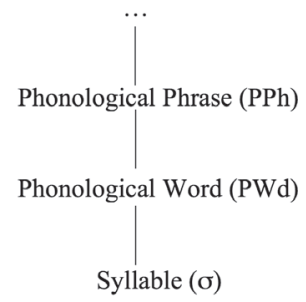

[the $[[$ dócu $]$ ment $]]$

[[dócu]ment]

[dócu]

do 
Despite the fact that CF seems to have no word-internal constituency, CF learners of English are able to acquire feet: in our results, L2ers exhibit target-like rhythmic patterns and stress, and use duration and intensity to signal both primary and secondary stresses in a way that mirrors what is observed in our English control data. This indicates that, even though foot structure seems to be absent in the speakers' L1 (see Özçelik 2011), they are able to acquire it in an L2. Pitch also seems to be used to signal primary stress, which is consistent with previous studies on English stress.

To conclude, the results indicate that, while word-level prominence and word-internal constituency seem absent in our CF data, CF speakers are able to acquire word stress and foot structure in English. Furthermore, the L2ers produce English stress with target-like rhythmic patterns and, as observed in our English control data, use both duration and intensity to signal word-internal prominence.

\section{Acknowledgements}

We would like to thank Heather Goad, Annie Tremblay, Peter Milne and Jeffrey Lamontagne for their feedback.

\section{Appendix: Unique Items Analysed in Each Task}

Note: Repeated and inflected (pluralized) words are not shown.

French Words

\begin{tabular}{|l|l|l|l|l|}
\hline maison & dernière & bâtiment & moderne & élégant \\
président & dernier & période & heureuse & maladie \\
nouvelle & mauvaise & touriste & portugaise & historique \\
première & premier & donneur & garçon & vanille \\
fabrique & gâteau & cuisine & fromage & central \\
jolie & nouveau & fondateur & chanson & fâché \\
mauvais & étrange & famille & japonais & comptable \\
morceau & bureau & province & dessin & repoussant \\
chocolat & plateau & prospère & tropicale & colorée \\
\hline
\end{tabular}




\section{English Words}

\begin{tabular}{|l|l|l|l|l|}
\hline damage & reasonable & general & fully & hospital \\
hurricane & hypothesis & ridiculous & request & presumably \\
completely & president & assaults & academic & comment \\
senator & quality & garage & minister & family \\
reasonably & possibly & probably & economy & attack \\
positive & analysis & event & director & soldiers \\
support & salute & different & negative & recruit \\
pyramids & complete & substance & decent & antique \\
chemical & adorable & impressive & orchestra & musician \\
pollution & review & division & frequent & cousins \\
inferior & eclipse & defeat & promise & miserable \\
physicians & impressively & dramatic & intelligent & garages \\
\hline
\end{tabular}

\section{References}

Altmann, H. (2006). The Perception and Production of Second Language Stress: A Crosslinguistic Experimental Study. PhD Dissertation, University of Delaware.

Armstrong, S.D. (1999). Stress and Weight in Québec French. MA Thesis, University of Calgary.

Beckman, M.E. (1986). Stress and Non-Stress Accent. Dordrecht: Foris Publications.

Chomsky, N. and Halle, M. (1968). The Sound Pattern of English. New York: Harper and Row.

Fry, D.B. (1955). Duration intensity as physical correlates of linguistic stress. Journal of the Acoustical Society of America, 32: 765-9.

Fry, D.B. (1958). Experiments in the perception of stress. Language and Speech 1: $126-52$.

Garde, P. (1968). L'Accent. Paris: Presses Universitaires de France.

Goad, H. and Buckley, M. (2006). Prosodic structure in child French: Evidence for the foot. Catalan Journal of Linguistics 5: 109-42.

Goad, H. and Prévost, A.-E. (2011). A Test Case for Markedness: The Acquisition of Québec French Stress. Unpublished Manuscript.

Grimson, A. (1980). An Introduction to the Pronunciation of English (3rd edition). London: Edward Arnold.

Gussenhoven, C. (2004). The Phonology of Tone and Intonation. Cambridge: Cambridge University Press.

Halle, M. and Vergnaud, J. R. (1987). An Essay on Stress. Cambridge, MA: MIT Press.

Harrington, J., Beckman, M.E., Fletcher, J. and Palethorpe, S. (1998). An electropalatography, kinematic, and acoustic analysis of supralaryngeal correlates of word and utterance-level prominence contrasts in English. In Proceedings of the 1998 International Conference on Spoken Language Processing, Vol. 5, 18511854. Sydney, Australia. 
Hayes, B. (1982). Extrametricality and English stress. Linguistic Inquiry 13: 227-76. Jun, S.-A. and Fougeron, C. (2000). A phonological model of French intonation. In Botinis, A. (ed.), Intonation: Analysis, Modelling and Technology, 209-42. Dordrecht: Kluwer.

Laver, J. (1994). Principles of Phonetics. Cambridge: Cambridge University Press.

Lehiste, I. (1976). Influence of fundamental frequency pattern on the perception of duration. Journal of Phonetics 4: 113-17.

Liberman, M. and Prince, A. (1977). On stress and linguistic rhythm. Linguistic Inquiry 8: 249-336.

Lieberman, P. (1960). Some acoustic correlates of word stress in American English. Journal of the Acoustical Society of America 32: 451-4.

Milne, P. (2012). SPLaligner, an Automatic Forced Alignment System for French.

Nespor, M. and Vogel, I. (1986) Prosodic Phonology. Dordrecht: Foris.

Özçelik, Ö. (2011). Representation and Acquisition of Stress: The Case of Turkish. PhD Dissertation, McGill University, Montreal.

Paradis, C. and Deshaies, D. (1990). Rules of stress assignment in Québec French: evidence from perceptual data. Language Variation and Change 2: 135-54.

Plag, I., Kunter, G., and Schramm, M. (2011). Acoustic correlates of primary and secondary stress in North American English. Journal of Phonetics 39(3): 362-74.

Selkirk, E. O. (1980). On prosodic structure and its relation to syntactic structure. Indiana University Linguistics Club.

Selkirk, E. O. (1984). Phonology and Syntax: the Relation Between Sound and Structure. Cambridge, MA: MIT Press.

Selkirk, E. O. (1986). On derived domains in sentence phonology. Phonology 3: 371-405.

Thibault. L. and Ouellet, M. (1996). Tonal distinctions between emphatic stress and pretonic lengthening in Quebec French. Proceedings of the International Conference on Spoken Language 96, Philadelphia, 2: 638-41.

Tremblay, A. (2007). Bridging the Gap between Theoretical Linguistics and PsychoLinguistics in L2 Phonology: Acquisition and Processing of Word Stress by French Canadian L2 Learners of English. PhD Dissertation, University of Hawaii at Manoa.

Tremblay, A. (2008). Is second language lexical access prosodically constrained? Processing of word stress by French Canadian second language learners of English. Applied Psycholinguistics 29: 553-84.

Tremblay, A. and Owens, N. (2010). The role of acoustic cues in the development of (non-)target-like second-language prosodic representations. The Canadian Journal of Linguistics 55(1): 85-114.

Vogel, I. (2009) The status of the Clitic Group. In Grijzenhout, J. and Kabak, B. (eds.), Phonological Domains: Universals and Deviations. Berlin: Mouton de Gruyter.

Walker, D.C. (1984). The Pronunciation of Canadian French. Ottawa: University of Ottawa Press. 